\title{
Role of Academic Stress as Predictor of Test Anxiety among University Students
}

\author{
Mussarat Jabeen Khan ${ }^{1}$, Farah Shamim ${ }^{2}$, Bushra Naeem ${ }^{3}$
}

\begin{abstract}
The basic purpose of the present research is to examine the role of academic stress as a predictor of test anxiety among university students. Correlational research design was used among various types of Quantitative research designs. Convenience sampling technique was used to approach sample. The sample consisted of 150 university students taken from various universities of Islamabad and Rawalpindi. Academic Stress Scale and Test Anxiety Inventory were used to collect data. Different type of statistics was used to analyze the data. Simple Linear Regression analysis was used to examine the role of academic stress as predictor of test anxiety. Results show that academic stress is the predictor of test anxiety among university students. Moreover, t-test analysis was used and the outcomes indicate that female students experience more academic stress than male students while there is non-significant difference among male and female university students on test anxiety. Non-significant differences were observed among students having 14 years and 16 years of education on academic stress and test anxiety. This study has strong implications in terms of academic stress and test anxiety in Pakistani society. It is recommended to initiate consultation seminars and workshops to create awareness and control academic stress to reduce test anxiety among students.
\end{abstract}

Keywords: Academic Stress, Test Anxiety, University Students

\section{Introduction}

Stress is a pressure that interferes with normal functioning of everyday activities. Academic stress is related to academic demands from students because they go through a number of activities for accomplishing their academic goals for example assignments, home works, quizzes, buying syllabus books, final exams, grades, teachers and parents' expectations and others (Kumar, Jain, \& Hegde, 2012). Anxiety when reached to a certain level disturbs the normal life activities (Quince, Wood, Parker, \& Benson, 2012). Students experience anxiety during

\footnotetext{
${ }^{1}$ Lecturer, Department of Psychology, IIUI Email: mussarat.jabeen@iiu.edu.pk

${ }^{2}$ MS Scholar, National Institute of Psychology, Quaid-i-Azam University Islamabad Email: farahdd1@gmail.com

${ }^{3}$ BS Scholar, Department of Psychology, IIUI Email: bushranaeem03@gmail.com
} 
the course of their study due to the number of pressures they face throughout the academic years like anxiety during exams.

Academic stress and test anxiety are interrelated and mostly occur together. Academic stress is manifested in the form of test anxiety (Wang \& Ding, 2003). Students have a lot of academic stressors due to which they experience anxiety for tests or exams and they find themselves in awkward positions while dealing with this anxiety during exams. Academic stress and test anxiety are no doubt one of the vastly studied topics in the field of research but their potential effect on one another is least studied (Sidana, Kishore, Ghosh, Gulati, Jiloha, \& Anand, 2012). Academic stress is the triggering factor for test anxiety (Xiao, 2013). Auerbach and Gramling (1998) concluded that a person has possibility to have anxious feelings, difficulty to pay attention or recall because of being in stress. Stress can change people's behaviors, like nail biting, rapid breathing, high heartbeat, teeth clenching and hand shaking. During stress people have cold feet and hands, stomach butterflies and rapid heartbeat which lead to the anxious emotions.

\subsection{Objectives of Study}

The main objectives of the present research are:

1. To examine the relationship between academic stress and test anxiety among university students

2. To explore the effect of demographic variables like gender and education on academic stress and test anxiety.

\subsection{Hypotheses of Study}

$\mathrm{H}_{1}$ : Academic stress predicts test anxiety among university students

$\mathrm{H}_{2}$ : Female students experience more academic stress and test anxiety than male students

$\mathrm{H}_{3}$ : Students with 14 years of education experience have higher academic stress and test anxiety than students with 16 years of education experience

\section{Literature Review}

Misra, McKean, West, Russo and Misra (2000) carried out a study surveying 249 college students at Midwestern University. The study indicated that anxiety, ineffective management of time and lack of satisfactory activities outside the academic environment were strong factors for academic stress. Time management has a high buffering effect on academic stress than does the leisure satisfaction activities. The study also revealed that as female students more effectively manage their time than male students, so they experience more stress and anxiety. Struthers, Perry and Menec (2000) predicted that academic stress and course grade relation is mediated by coping style and motivation of students. 
Findings of research showed that academic stress in students is inversely related with course grades.

Xiao (2013) reported that academic stress is extremely high in Chinese students because they are expected to achieve academic success to gain prestige, family approval, and social support resulting in very high academic demands excessive pressure on adolescents and school children. Academic stress has many negative outcomes, like anxiety and low academic performance. Academic stress is positively related to test anxiety in students and inversely related with their test performance. Test anxiety is inversely related to test performance. Results further showed that active coping did not affect the relation of academic stress, academic performance and test anxiety. Perceived parent and social support moderated the relationship of test anxiety and academic stress and also the relationship of test performance and test anxiety.

Survey of college students reported that in any given time 10 to $20 \%$ population of students is facing psychological issues (Stress, Depression and Anxiety). The paper shortly describes the research carried out regarding stress, depression and anxiety, showing how counseling helps students with emotional issues and also discussed some preventive measures that should be promoted in colleges like arranging counseling centers for students; creating awareness in college students for seeking help from counseling centers. List of psychological issues was given which along with depression; eating problems also included anxieties about studies like about exams, tests and presentations (Kumaraswamy, 2013).

Pakistani researches also revealed similar results as Hashmat, Hashmat, Amaanullah and Aziz (2008) found that factors that cause exam anxiety among medical students are extensive load of syllabus, lacking in exercise, long time periods for exams. Farooqi and Ghani (2012) concluded that female students usually have higher level of anxiety than male students in medical colleges. Moreover the results revealed that male students score relatively higher Grade Point Average (GPA) than female students. Further test anxiety was found to be negatively related to academic performance. Wang and Ding (2003) concluded that academic stress in college students is positively correlated to test anxiety. According to American College Health Association (2006) 14,873 students face anxiety disorders and issues of depression i.e. $15.7 \%$ in top ten reported health obstructions in academic performance of student. Zhao, Xu, and Xie (2006) studied that in students of secondary school academic stress was remarkably and positively related to their level of anxiety during the phase of stressful exams. Khalid and Hasan (2009) reported that test anxiety is more in low achievers than 
in high achievers. High achievers females have more test anxiety as compared to high achievers males.

Nadeem and Sansgiry (2012) concluded that academic performance of students is related to their time management, test competence and test anxiety. And these factors are also determinants of low and high achievement in terms of GPA. Sultan (2012) reported that students who perceive low level of competence have more anxious feelings than students who perceive high competence. Further, gender differences were found for instances male students are more competent so they experience less anxiety, less feelings of negative evaluation and less language learning anxiety than female students. Harpell and Andrews (2013) found that there is a significant relation between test anxiety inventory and school survey scales. It is analyzed through linear regression process that academic stress and age predict worry, anxiety, academic self-concept, emotional, physiological and academic stress along with age predict test anxiety.

Students are the society important investment and asset for future. Their mental health is important not only for their own sake but also as a contributing factor to the wellbeing of society in large (Euma \& Ricea, 2011). Academic stress may lead students towards many psychological health issues like anxiety, depression, aggressive behavior or suicide attempts etc. which is very alarming for society as a whole (Heng-Tsung, \& Shao-Ting, 2013). Present research attempts to find the relationship between academic stress and test anxiety which will be helpful for the current body of knowledge especially in the context of Pakistan because previous researches which have been reviewed contain these variables but have not found relationship between academic stress and test anxiety. There can be many moderating or mediating variables which will describe this correlation like motivation, coping strategies and others. But the basic is to conduct an authentic research on academic stress and test anxiety. Moreover, this research would assist teachers and higher authorities of colleges and universities in policy formation and curriculum management to reduce the stress which occurs through tests, assignments, exams so that students do not get anxious and go for wrong ways to overcome their anxiety.

\subsection{Research Design}

\section{Research Methodology}

Correlational research design was used among different types of Quantitative research design. Quantitative methodology would best apply to this type of research. A quantitative approach allows the researcher to examine the relationship between the variables. The data can be used to make predictions. 


\subsection{Sample \& Sampling Technique}

The sample was consisted of 150 university students (75 males and 75 females), selected from different universities of Islamabad and Rawalpindi including International Islamic University, Virtual University and Institute of Space Technology. Age ranges from 18 to 25 years. Students were approached using convenience sampling technique. Convenience Sampling is affordable, easy and the subjects are readily available. The main objective of convenience sampling is to collect information from participants who are easily accessible to the researcher.

\subsection{Instruments}

\subsubsection{Test Anxiety Inventory}

It was developed by Spielberger et al. (1980). This inventory measures test anxiety among students. It is a 4 point rating scale ranging from almost never to almost always. $1=$ almost never, $2=$ sometimes, $3=$ often, $4=$ almost always. It consists of 20 items. Cronbach Alpha Reliability of test anxiety inventory is 0.89 .

\subsubsection{Academic Stress Scale}

It was developed by Kohn and Frezer (1986). This inventory measures academic stress in students due to exams, quizzes, assignments and others. It is a 5 point rating scale ranging from not at all stressful to extremely stressful. $1=$ not at all stressful, $2=$ rarely stressful, $3=$ sometimes stressful, $4=$ fairly stressful, $5=$ extremely stressful. It consists of 18 items. Cronbach Alpha Reliability of academic stress scale is 0.86 .

\subsection{Data Collection}

Students were approached from different institutions by taking permission from the heads of institutes. Participants were assured that collected data would be used only for research purpose. Students were requested to respond to a set of questionnaire to indicate "how they feel most of the times". Students were allowed to take maximum time to respond as per their convenience. After completion, the set of questionnaire was collected for analysis.

\section{Data Analysis and Interpretation}

Simple Linear Regression analysis was used to examine the role of academic stress as predictor of test anxiety. Moreover, t-test was used to compare difference between male and female university students on academic stress and test anxiety. 
Table 4.1

Simple Linear Regression showing Academic Stress as Predictor of Test Anxiety $(N=150)$

\begin{tabular}{cccccc}
\hline & $\mathrm{B}$ & $\mathrm{SEB}$ & $\mathrm{B}$ & $\mathrm{t}$ & $\mathrm{p}$ \\
\cline { 2 - 6 } Constant & 15.41 & 3.49 & & 4.40 & .000 \\
Academic stress & .54 & .06 & .58 & 8.67 & .000 \\
\hline
\end{tabular}

$\mathrm{R}=.58, \mathrm{R}^{2}=.33$

Table shows the effect of academic stress on test anxiety among university students. Academic stress significantly leads to test anxiety. There is a positive correlation between academic stress and test anxiety $(\beta=.58, \mathrm{t}=8.67$, $\mathrm{p}=.000$ ). Academic stress causes $33 \%$ variance in test anxiety.

Table 4.2

Difference between Male and Female University Students on Academic Stress and Test Anxiety $(N=150)$

\begin{tabular}{|c|c|c|c|c|c|c|c|}
\hline & Male & Female & & & & & \\
\hline & $\mathrm{M}(\mathrm{SD})$ & $\mathrm{M}(\mathrm{SD})$ & $\mathrm{t}$ & $\mathrm{p}$ & $\overline{\mathrm{LL}}$ & UL & Cohen's d \\
\hline $\begin{array}{l}\text { Academic } \\
\text { Stress }\end{array}$ & $\begin{array}{c}51.53 \\
(11.89)\end{array}$ & $\begin{array}{c}58.21 \\
(10.74)\end{array}$ & 3.60 & .000 & 10.36 & 3.02 & 0.59 \\
\hline Test Anxiety & $\begin{array}{l}44.87 \\
(9.24)\end{array}$ & $\begin{array}{c}45.33 \\
(12.42)\end{array}$ & 2.61 & .794 & 3.99 & 3.07 & 0.42 \\
\hline
\end{tabular}

Table shows the difference between male and female university students on academic stress and test anxiety. Female university students have more academic stress $(\mathrm{M}=58.21, \mathrm{SD}=10.74)$ than male university students $(\mathrm{M}=51.53$, $\mathrm{SD}=11.89$ ). However, there is non-significant difference between male and female university students on test anxiety.

Table 4.3

Difference between University Students having 14 and 16 years of Education on Academic Stress and Test Anxiety $(N=150)$

\begin{tabular}{|c|c|c|c|c|c|c|c|}
\hline \multirow[b]{3}{*}{$\begin{array}{l}\text { Academic } \\
\text { Stress }\end{array}$} & \multirow{2}{*}{$\begin{array}{l}\text { 14years } \\
(\mathrm{n}=120)\end{array}$} & \multirow{2}{*}{$\begin{array}{c}16 \text { years } \\
(\mathrm{n}=29)\end{array}$} & \multicolumn{5}{|c|}{$95 \% \mathrm{CI}$} \\
\hline & & & $\mathrm{t}$ & $\mathrm{p}$ & LL & UL & Cohen's d \\
\hline & $\begin{array}{c}55.72 \\
(11.71)\end{array}$ & $\begin{array}{c}51.48 \\
(11.67)\end{array}$ & 1.75 & .082 & .55 & 9.02 & 0.28 \\
\hline $\begin{array}{l}\text { Test } \\
\text { Anxiety }\end{array}$ & $\begin{array}{c}45.16 \\
(11.09)\end{array}$ & $\begin{array}{c}44.72 \\
(10.48) \\
\end{array}$ & .19 & .849 & 4.06 & 4.92 & 0.03 \\
\hline
\end{tabular}

Table shows non- significant difference between University students having 14 years and 16 years of education on academic stress and test anxiety. 
Findings of the study indicate that academic stress significantly leads to test anxiety. Gender differences were also considered that female university students have high level of academic stress than male university students. However, there is non-significant difference between male and female university students on test anxiety. An effort was made to study the difference in academic stress and test anxiety among students having 14 years and 16 years of education. Results also show non- significant difference between University students having 14 years and 16 years of education on academic stress and test anxiety.

\section{Discussion}

According to the first hypothesis, academic stress leads to test anxiety among university students. Results showed a positive correlation between academic stress and test anxiety. It is consistent with existing literature as Xiao (2013) stated that academic stress is positively related to test anxiety in students and inversely related with their test performance.

According to second hypothesis, female students have more academic stress and more test anxiety than male students. Results showed that female University students have more academic stress than male university students. It is also consistent with current literature as Abulghani, Alkanhal, Mahmoud, Ponnamperuma and Alfaris (2011) found that there is higher prevalence of stress among females than in males. Non-significant difference was found between male and female students on test anxiety. Nowadayss, female students want to compete with male students in education as well as in other fields. Female students perceive themselves as active and as capable as male students and show non-significant difference in test anxiety than male students.

According to the third hypothesis, students having 14 years of education have more academic stress and more test anxiety than students having 16 years of education. Results showed non-significant difference between University students having 14 years and 16 years of education on academic stress and test anxiety. As this study was conducted in Islamabad where higher education is preferred, students are eager to complete their higher education as soon as possible for the sake of securing future career for which students having 14 and 16 years of education resist academic stress and test anxiety. Thus, students currently having 14 years of education are enthusiastic about getting in 16 years of education and even more. Moreover, students are encouraged by parents and society to continue education till higher level due to which there is nonsignificant difference between students having 14 and 16 years of education on academic stress and test anxiety. 


\section{Conclusion}

Findings indicate that academic stress leads to test anxiety among (location of the university) university students. Female students experience more academic stress than male students. On the other hand, non-significant difference was found in students with 14 years and 16 years of education on academic stress and test anxiety.

\section{Recommendations}

Academic centers are the ideal place in which to conduct stress intervention and prevention programs because so many stressors are directly related to the academic environment and these stressors affect students' performance in academic center. In response to high levels of students anxiety disorders, depression, substance abuse, and disengagement, educators and health specialists creating research-based intervention at the academic centers . The initiative, challenge success, works with academic center to design and implement site-based policies and practices that may reduce student stress and promote greater student engagement, academic integrity, and physical and mental health.

\subsection{Limitations and Suggestions}

Present research has some limitations. Recommendations for future research are explained in this subsection;

1. Sample size was small due to which results of this research are less generalizable for the population of all university students. Studies conducted with large sample size will be more preferable.

2. Data were collected from universities only in Islamabad. It is suggested that future studies could be conducted in other universities throughout Pakistan.

3. Present research is conducted only on university students. Other researchers could cconduct similar researches at other levels namely school and college level.

\section{Implications of Study}

University educators, administrators and students could benefit from this research as it reveals the underlying cause of test anxieties in students which are no doubt the most important asset of our society. It also helps university curriculum management authorities to effectively organize syllabus and schedules so that students suffer from minimum possible academic stress and test anxiety. Students can reduce their test anxiety by controlling their stress of completing their assignments, presentations, tests, GPA, grades and others. In addition, female students who have generally high level of academic stress could 
help themselves by reducing their stress in order to perform better in their academic settings.

\section{References}

Abulghani, H. M., Alkanhal, A. A., Mahmoud, E. S., Ponnamperuma, G. G., \& Alfaris, E. A. (2011). Stress and Its Effects on Medical Students: A Cross-Sectional Study at a College Of Medicine in Saudi Arabia. Journal of Health, Population and Nutrition, 29(5), 516-522.

American College Health Association. (2006). National College Health Assessment. Reference Group Data Report (Abridged). Journal of American College Health, 56(5), 469-479.

Auerbach, S. M., \& Gramling, S. E. (1998). Stress management: psychological foundations. New Jersey Prentice Hall.

Euma, K., \& Ricea, K.G. (2011). Test anxiety, perfectionism, goal orientation, and academic performance. Anxiety Stress Coping, 24(2), 167-178.

Farooqi, Y. N. \& Ghani, R. (2012). Gender Differences in Test Anxiety and Academic Performance of Medical Students. International Journal of Psychology and Behavioral Sciences, 2(2), 38-43.

Harpell, J. V. \& Andrews, J. W. (2013). Relationship between School Based Stress and Test Anxiety. International Journal of Psychological Studies, $5(2), 74-82$.

Hashmat, S., Hashmat, M., Amanullah, F., \& Aziz, S. (2008). Factors Causing Exam Anxiety in Medical Students. Journal of Pakistan Medical Association, 58(4), 167-170.

Heng-Tsung, D.H., \& Shao-Ting, A.H. (2013). Comparing the effects of test anxiety on independent and integrated speaking test performance. TESOL Q, 47(2), 244-269.

Khalid, R. \& Hasan, S. S. (2009). Test Anxiety in High and Low Achievers. Pakistan Journal of Psychological Research, 24(2), 97. 
Kohn, J. P. \& Frazer, G. H. (1986). An academic stress scale: Identification and rated importance of academic stressors. Psychological Reports, 59, 415426.

Kumar, G. S., Jain, A., \& Hegde, S. (2012). Prevalence of depression and its associated factors using Beck depression inventory among students of a medical college in Karnataka. Indian Journal of Psychiatry, 54(3), 223226.

Kumaraswamy, N. (2013). Academic Stress, Anxiety and Depression among College Students. International Review of Social Sciences and Humanities, 5(1), 135-143.

Misra, R., McKean, M., West, S., \& Russo, T. (2000). College Students' Academic Stress and its Relation to their Anxiety, Time Management, and Leisure Satisfaction. American Journal of Health Studies Audience, 16(1), 7-15.

Nadeem, T. \& Sansgiry, S. S. (2012). Determinants of Academic Performance in University Students. Pakistan Journal of Psychological Research, 27(2), 265- 278.

Quince, T. A., Wood, D. F., Parker, R.A., \& Benson, J. (2012). Prevalence persistence of depression among undergraduate medical students: a longitudinal study at one UK medical school. British Medical Journal, 2(4), 1-8.

Sidana, S., Kishore, J., Ghosh, V., Gulati, D., Jiloha, R.C., \& Anand, T. (2012). Prevalence of depression in students of a medical college in New Delhi: a cross-sectional study. Australian Medical Journal, 5(5), 247-250.

Spielberger, Gonzalez, H. P., Taylor, C. G, Anoton, W. D., Algaze, B., Ross, G. K. \& Westberry, L. G. (1980). Test Anxiety Inventory. Palo Alto, CA: Consulting Psychologists Press.

Struthers, C. W., Perry, R. P., \& Menec, V. H. (2000). An Examination of the Relationship among Academic Stress, Coping, Motivation, and Performance in College Source. Research in Higher Education, 41(2), 581-592. 
Sultan, S. (2012). Students' Perceived Competence Affecting Level of Anxiety in Learning English as a Foreign Language. Pakistan Journal of Psychological Research, 27(2), 225-239.

Wang, J. \& Ding, X. (2003). A Study on the Influential Factors on Anxiety of Secondary School Students. Chinese Journal of Clinical Psychology, 11(3), 164-166.

Xiao, J. (2013). Academic Stress, Test Anxiety and Performance in Chinese High School Sample: the Moderating Effect of Coping Strategies and Perceived Social Support (Unpublished Dissertation) Georgia State University

Zhao, J., Xu, J. \& Xie, Y. (2006). Research on College and University Students' Self-Reported Health Problems. Chinese Journal of Behavioral Medical Science, 15(6), 546-548. 